\title{
Life-Areas and How to Estimate Greenhouse Gas Emission Footprints
}

This chapter ${ }^{1}$ now turns to the problem of identifying relevant areas of social life that are climate-relevant and how to estimate the greenhouse gas (GHG) emissions and energy demands of specific behaviors. There are a growing number of footprinting tools, most of which can be found on the internet, which claim to provide a sufficiently good approximation of the $\mathrm{CO}_{2}$ budget, the ecological footprint or one's own carbon footprint with only a few pieces of information. Paul Padgett and colleagues (2008) were able to show in a comparison of such calculators, most of which are designed for private use, that the results sometimes differ greatly depending on which calculation formulas are used with which behavioral questions and with which conversion factors. For a more recent compilation and rating of 31 footprint calculators, I recommend reading Mulrow et al. (2019).

From a scientific point of view, such tools are sometimes met with criticism because the calculation methods used are not sufficiently transparent (Čuček et al., 2012). However, the general purpose of such calculators is to raise awareness of the emissions associated with one's own behavior. Popular calculators in the Austrian context-and here, of course, the national background is important-are those of the Global Footprint Network (https://www.footprintcalculator.org) and the calculators of the Austrian Federal Ministry for Climate Protection, Environment, Energy, Mobility, Innovation and Technology (https://www.mein-fussabdruck.

\footnotetext{
${ }^{1}$ Lead author: David Neil Bird; "I" throughout this chapter refers to the lead author.
}

(C) The Author(s) 2022

M. Hadler et al., Surveying Climate-Relevant Behavior, https://doi.org/10.1007/978-3-030-85796-7_3 
at/), and JOANNEUM RESEARCH (https://www.lifestylecheck.at/). As one might expect, they do not all give the same estimate. This is because the footprint analyst and website designer must make decisions about what type of emissions to estimate and on which sectors of the society and economy to focus. Due to these decisions, trade-offs are made between accuracy and the level of detail of the emissions inventoried. In addition, there is often a problem that bottom-up emission estimates for individuals may not match average per person emissions in the national inventory.

In this chapter, we will investigate solutions to these questions and present a method for reconciling these problems. We will start by coming from the top-down, discussing what type of emissions should be used for footprinting, and present which sectors of society and the economy should be the focus of the footprint. This will be followed by the formulation of a generalized bottom-up method for estimating and categorizing emissions from everyday life, and the chapter will end by presenting an actual calculation and the tie between the top-down and bottom-up estimates.

\subsection{What Type of Emissions to Use, Which Sectors Should Be the Focus}

The GHG emission estimates, prepared yearly, in a country's national GHG inventory follow the Intergovernmental Panel on Climate Change (IPCC) guidelines (2006). The inventories are prepared by collating information on activities, such as the combustion of liquid fuels, that occur within the country's borders and multiplying these values by country-specific emission factors. Although the national inventory should capture all GHG emissions that occur within the country, there is no linking of activities. For example, a consumer's decision to eat a piece of cheese includes a chain of linked activities, that is, the cow must be fed, sheltered, and milked; the milk must be processed to cheese, cooled, and packaged; the cheese must be transported to and stored in the supermarket; the consumer needs to transport the purchased cheese to her/his home, where it is cooled; the plate must be washed; and the consumer's waste (packaging and defecation) must be disposed of. All these steps are linked to the consumer's decision, but they appear as separate items in the national inventory. The recognized method for estimating the emissions from the piece of cheese is the life-cycle assessment (LCA). The European Environment Agency defines LCA as 
a process of evaluating the effects that a product has on the environment over the entire period of its life thereby increasing resource-use efficiency and decreasing liabilities. It can be used to study the environmental impact of either a product or the function the product is designed to perform. LCA is commonly referred to as a "cradle-to-grave" analysis.

In addition, some of the emissions may occur outside the nation's boundary and will not appear in the national inventory. The national inventories are production-based, whereas what is need for a proper estimate of a consumer's footprint is a consumption-based inventory (Peters, 2008; Davis \& Caldeira, 2010). The EU's Green Deal is facing criticism because it considers production-based emissions only (Fuchs et al., 2020). In the EU-28, the consumption-based inventory for 2016 is estimated as $5.6 \mathrm{Gt}$ $\mathrm{CO}_{2}$-eq., $27 \%$ higher than the production-based inventory (4.4 Gt $\mathrm{CO}_{2}$-eq.) (Wood et al., 2019). The consumption-based inventory is estimated top-down using multi-regional input-output (MRIO) economic models. The difference between the production-based and consumptionbased inventories will vary by country depending on its size and the relative proportion of imports and exports in its economy. For Austria, in 2017, using a bottom-up methodology (Windsperger et al., 2017; Jungmeier et al., 2020), I estimate that the consumption-based emissions (114.7 Mt. $\mathrm{CO}_{2}$-eq. or 13.1 t $\mathrm{CO}_{2}$-eq/person) are nearly $40 \%$ greater than the national inventory (82.3 Mt. $\mathrm{CO}_{2}$-eq. or $9.4 \mathrm{t} \mathrm{CO}_{2}$-eq./person). The consumption-based emissions are given by

\section{Consumption $_{y}=$ Production $_{y}+$ Imports $_{y}-$ Exports $_{y}$.}

The consumption-based inventory may be divided into six categories, as shown in Fig. 3.1 (left). Most emissions are caused by the consumption of goods $(39 \%)$, followed by mobility (33\%), housing (12\%), food (10\%), infrastructure $(5 \%)$, and waste management (1\%). The consumption category can be further subdivided into key consumption items (Fig. 3.1, right). In the diagram below, one can see that steel, food, and textiles all cause more than 1 t $\mathrm{CO}_{2}$-eq emissions per person. Please note that in Fig. 3.1 (left), food appears as a separate item. A general problem with bottom-up methods is that one cannot calculate the emissions for all items consumed due to limited data and the diminishing contributions of some

\footnotetext{
${ }^{2}$ https://www.eea.europa.eu/help/glossary/eea-glossary/life-cycle-assessment
} 

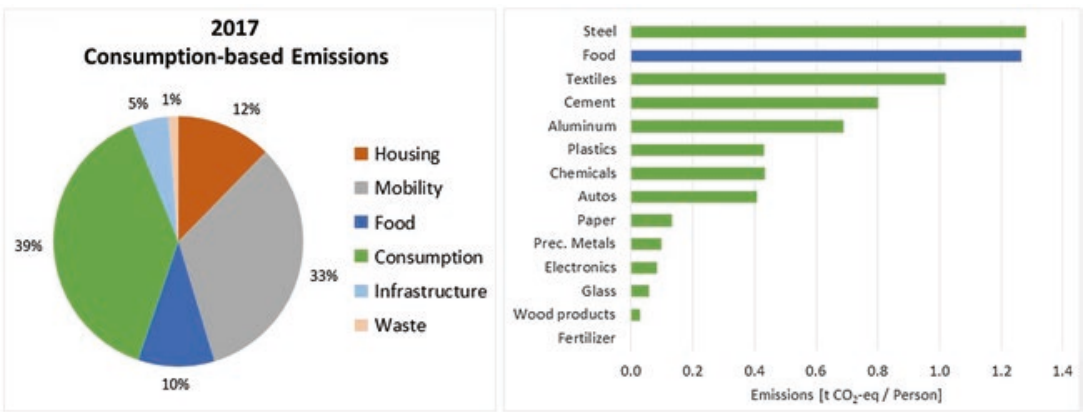

Fig. 3.1 Components of the consumption-based inventory (left) and emissions per person for various goods (right). (Source: Lead author's unpublished self-calculation)

items. There is a trade-off between level of detail and effort to collect the necessary data. This selection of items causes a truncation error, and one should use an IPCC key-category type analysis to identify products that should be included and keep the truncation error to an acceptable minimum (IPCC, 2006). We will visit this problem again when we discuss consumer footprinting.

So now, how does one convert a national consumption-based inventory to a meaningful indicator for personal footprinting? One method is to redo the categorization presented above into the six requirements of everyday life ("life-areas"). We suggest that an individual needs the following:

1. A place to live (housing);

2. To be able to get to work, the grocery store, and so on (mobility);

3. Nutrition (food and part of waste);

4. Clothing, books, furniture, and so on (parts of consumption and waste);

5. Information (parts of housing and infrastructure); and

6. Leisure (part of infrastructure).

Of course, there are gray areas in the categorization. For example, does one classify travel for a vacation as leisure or as mobility? The exact classification is not important as long as it is stated clearly and consistently applied. 
The personal footprint suffers from the same problem as the bottom-up consumption-based inventory. The analyst must select which items and services to include in the footprint. Hence, there is this trade-off between level of detail and effort to collect the necessary data. It is relatively easy to collect specific fairly detailed information on mobility and housing. For example, most people know how far they drive in a year, how much time they spend commuting per day, or how much area their dwelling has. It requires more effort by both the analyst and the individual to collect detailed information on nutrition and the consumption of goods and information. For nutrition, the analyst could require the individual to provide information in grams per week on the consumption of types of meats, dairy products, vegetables, grains, and fruits because that is how the analyst needs the information. However, it is a tedious task for the consumer to provide these data via food diaries, so "short-cuts" are probably made. For example, one could define standard eating styles based on the frequency of meat consumption in meals per week. The individual would need to choose which eating style best describes her/his lifestyle.

An important distinction between footprinting and consumption-based inventories is how the information may be used. As discussed in other chapters of this book, the footprint could be used to help an individual change her/his lifestyle or make daily consumer decisions. Hence, another consideration in choosing which items and services form the detailed part of the footprint is which life-areas have influence and which life-areas the individual can change.

For this reason, I suggest a large portion of the individual's footprint is a constant that reflects societal demand and not the individual's demand for certain goods and services. The consumption of items such as steel, cement, aluminum, some plastics, and chemicals fall into this group. These items are used in the construction of buildings and infrastructure in society. The analyst cannot ask the individual: "how much cement did you consume last year?" The individual will answer zero, but it is the largest contributor to consumption in the consumption-based inventory. Not only that, but the individual has a very limited ability to change the amount society consumes.

In this section, I have discussed what type of emissions should be used for footprinting and presented which sectors of society and the economy I believe should be the focus of the footprint. While it is relatively clear what type of emissions should be used (i.e., consumption-based using LCA), there really is no "right" or "wrong" selection. I made my selection of 
sectors and consumption items from a top-down analysis. The footprint analyst may have other reasons for choosing which sectors and consumption items appear in her/his analysis. However, the reasons should be clearly documented, and the analyst must always keep in mind that there are trade-offs between accuracy and expediency made with these decisions. In the next section, I will look at a general method for estimating emissions from the bottom up.

\subsection{A Generalized Method for Estimating EMISSIONS FROM A SERVICE}

The generalized approach for estimating GHG emissions from an activity or service is shown in Eq. 3.1:

$$
g_{i}=s_{i} x \eta_{i} x E F_{i}
$$

For item $i, g_{i}$ are the emissions from an amount of service $s_{i}$, which has an efficiency-related indicator $\eta_{\mathrm{i}}$, and an emission factor $E F_{i}$.

The footprint of a consumer is, then, the sum of the emissions from the individual services.

$$
G=\sum_{i} g_{i}
$$

One's choices, as a consumer, affect all three components of Eq. 3.1. One can consume less of the service, use a service from an efficiency system, and/or use a low emission fuel.

Using the generalized equation is the goal of footprint analysis. However, in practice, this equation is simplified as needed to fit the available information and simplify the data collection needs. This is better illustrated with specific examples from each of the life-areas.

\section{Mobility}

As a consumer, one requires a specific amount of transportation service $\left(s_{i}\right.$ in $\left.\mathrm{km}\right)$. This service is provided by, for example, a car, with an efficiencyrelated indicator $\left(\eta_{i}\right.$ in $\mathrm{MJ}$ per $\left.\mathrm{km}\right)$, and the energy is provided by a fuel with an emission factor $\left(E F_{i}\right.$ in $\mathrm{g} \mathrm{CO}_{2}$-eq per $\left.\mathrm{MJ}\right)$. For the individual's 
daily commute with multiple transportation modes, the generalized equation may need to be modified. The individual may know how much time he or she spends on a bus, in a train or subway, using a bicycle or walking. Each mode has its unique efficiency-related indicator and emission factor. In addition, LCA transportation studies often report $\mathrm{CO}_{2}$-eq emissions per passenger-km. Hence, the $\eta_{i} x E F_{i}$ term in Eq. 3.1 is replaced by $v_{i} x E F_{i}$ where $v_{i}$ is the average velocity of the mode of transport.

\section{Housing}

The consumer requires a specific amount of floor space to live as a service $\left(s_{i}\right.$ in $\left.\mathrm{m}^{2}\right)$. The energy demand for heat per unit floor space is the efficiencyrelated indicator $\left(\eta_{i}\right.$ in $\mathrm{MJ}$ per $\left.\mathrm{m}^{2}\right)$ that depends on the building envelope and heating system, and the emission factor $\left(E F_{i}\right.$ in $\mathrm{g} \mathrm{CO}_{2}$-eq per $\left.\mathrm{MJ}\right)$ is determined from the type of fuel that is used to provide the energy.

\section{Nutrition}

Every person needs a daily amount of food energy. This is supplied by a gamut of food types. Each food type, for example, legumes, provides a certain amount of food energy $\left(s_{i}\right.$ in kcal). The food has an efficiencyrelated indicator $\left(\eta_{i}\right.$ in $\mathrm{kg}$ per $\left.\mathrm{kcal}\right)$, and there is an emission factor to produce the required number of legumes $\left(E F_{i}\right.$ in $\mathrm{g} \mathrm{CO}_{2}$-eq per $\left.\mathrm{kg}\right)$.

Of course, to build an individual's footprint, it would be nice to know the amounts consumed of many food stuffs, but, without the individual filling out a detailed food consumption $\log$, this is beyond the knowledge of the individual. In addition, the emission factors for different foods within a food category are often similar (e.g., carrots and parsnips). Hence, the data collection may be simplified by assuming standardized dietary categories. For example, an individual may follow a vegan, vegetarian, or pescatarian lifestyle. If the person eats meat, then he/she may be asked their frequency of meat consumption by type from once a week to daily. In addition, emission factors differ for food stuffs depending on whether they come from organic or non-organic production. Hence, for nutrition, it is simpler to apply Eq. 3.1 to patterns of services that specify amounts of food stuffs. 


\section{Consumption}

Emissions from the consumption of goods come from many sources, and the individual may have limited knowledge about his/her consumption. For example, can you say how many tons of cement or steel you consumed last year? If you do know, could you change your lifestyle to reduce the emissions? The consumption of cement and steel (other than in vehicles) occurs primarily in the construction of buildings and infrastructure. In my experience assessing footprints, I have chosen not to focus on these items but rather allocate them to the individual as a societal "overhead." Instead, I have focused on the consumption of items that defines a person's lifestyle, including clothing, electronics, sporting goods, and vehicles. For example, are you a clotheshorse? An electrophile? A sport's buff? A petrohead? Once aware of the impact of her/his lifestyle, an individual can actively reduce his/her footprint.

Following Eq. 3.1, for these items, the service is the number of items (or fraction thereof) purchased per year. For clothing, this may be the number of shirts, jeans, underwear, shoes, sweaters, and outer garments purchased per year. A less detailed inventory may be quantified by asking the individual if they purchase more or less (as a range) clothing than their colleagues. Nevertheless, the answer must be converted to an amount of clothing $(\mathrm{kg})$ of various types, which the individual purchases based on some assumptions.

For electronic goods, a similar approach can be used. The individual can be asked how frequently they purchase a cell phone or flat screen monitor and whether they purchase new or used products.

This leads to the temporal aspects of the footprint. In LCA, the environmental impacts of a good or service are usually amortized over the lifetime of the good or service, where lifetime may be in terms of time (e.g., years) or service (automobile lifetime in kilometers). For footprints, we are interested in time-average emissions even though there may be a large temporal variation in emissions. For example, if you moved into a newly constructed apartment this year, your instantaneous footprint is dominated by this purchase, and as discussed above, its construction and the emissions thereof form a significant component of one's footprint. However, as I have chosen to assign these as a societal burden, and applying ergodic theory, spatial and time averages are equivalent. In general, I propose that there are the following three types of consumer goods: 
1. Items of which an individual has one. These are discarded and replaced after a useful lifetime. They are rarely traded for reuse by another consumer. An example of a type 1 item is one's cell phone.

2. Items of which the individual has many, but only one may be used at one time. New units are purchased regularly but rarely when the old is discarded for reasons other than end-of-life. Hence, the true lifetime of the unit is longer than the useful lifetime, and units are stockpiled. An example of a type 2 item is a pair of jeans.

3. Items of which the individual has one, and it is replaced for reasons other than end-of life, but the item is not discarded. It is traded to a second consumer. Probably the most important type 3 item is an automobile.

For each of these types of consumer goods, I suggest that their footprints are estimated using different temporal methods. This is partly due to their nature but also due to the individual's knowledge of her/his consumption.

For type 1 consumer goods, the annual emissions are calculated using simple amortization. The individual knows fairly well the typical lifetime of the item. Simple amortization is used in LCA. However, simple amortization has its drawbacks (see, e.g., the discussion about emissions from bio-based products in Liptow et al., 2018).

I prefer, and recommend, using the instantaneous annual emissions for type 2 items. The annual emissions are calculated from the annual consumption of the item. For example, the individual is asked how many pairs of jeans he/she bought last year. My recommendation is based on two points. Firstly, the individual has this knowledge, while they may not be able to answer how long a pair of their jeans lasts. Secondly, the purchase of new items may extend the lifetime of the existing items. For example, the new pair of jeans is worn instead of the older pair of jeans, but the older pair is not discarded. Its lifetime is extended even though that may mean that the pair of jeans collects dust in the consumer's closet.

Consumer goods of type 3 , in particular automobiles, are a bit of a problem. The conventional simple amortization means that the individual is allocated a fraction of the emissions for the vehicle dependent on the lifetime of the vehicle independent of whether he/she drives a new or used car. This means that there is no footprint surcharge for frequently purchasing a new vehicle, which is not a lifestyle that we wish to promote, from my perspective. If fact, I argue that the purchase of a new car may 
temporarily create an oversupply of used cars, lowering their price. This may ripple through the used car market until an individual with a vehicle near end-of-life decides that it is now cheaper to purchase a new (to them) used car instead of repairing her/his existing one. As a result, I argue that the purchase of a new car shortens the lifetime of a used car and increases the individual's footprint. Figure 3.2 is the author's modeled impact of frequency of new car purchase. I assume that the individual receives credit for her/his old car when she/he purchases a new one and that vehicles are subject to exponential decay (as a constant percentage of vehicles is lost each year due to accidents, etc.).

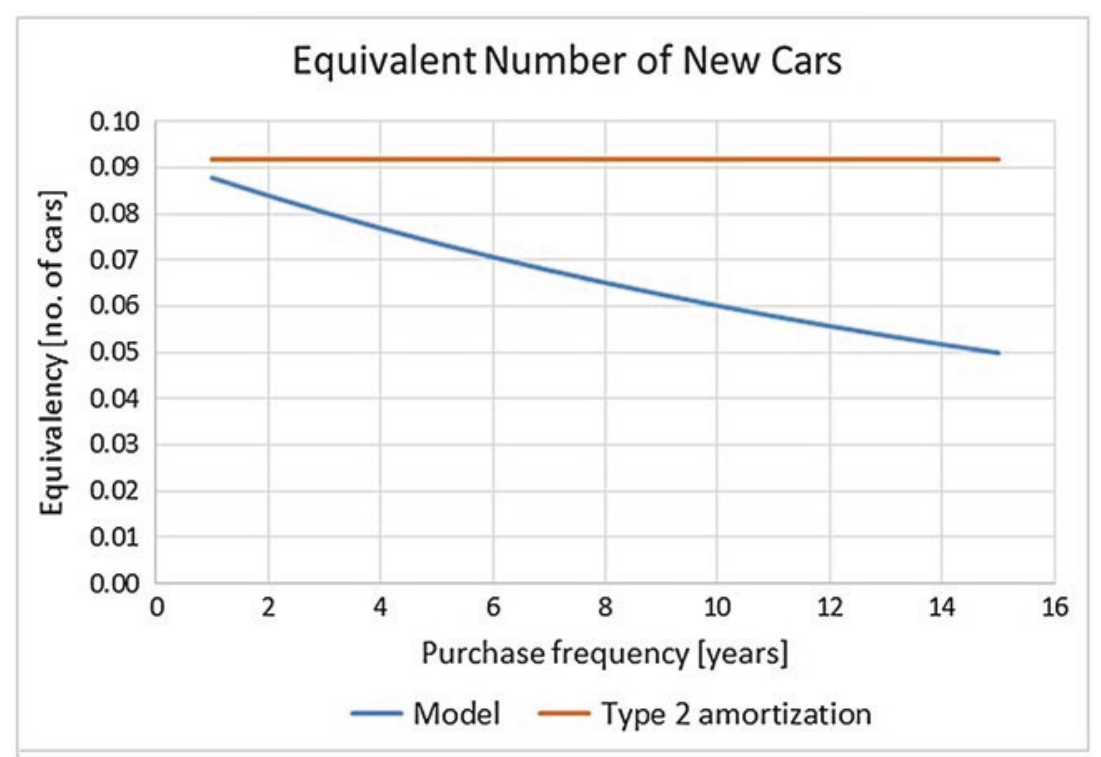

Fig. 3.2 Equivalent number of new cars as a function of new car purchase frequency. In Austria, based vehicle registrations, the average age of the automobile fleet is 7.4 years, and the average age of the fleet in the EU in 2018 is 10.9 years. The difference is due to the export of used cars. (Source: Lead author's unpublished self-calculation) 


\subsection{Melding BotTom-Up Footprints with Top-Down Average Per Person Emissions}

As I have tried to show, there is no "right" or "wrong" method for GHG footprinting. The analyst has to make decisions on what activities and consumption items to include and how to include them. These decisions are based on the analyst's perception of the individual's knowledge and timetolerance, prior understanding of the important components of the footprint in her/his country and wish to focus on a specific lifestyle item. For example, micro-plastics have recently been in the public focus. They may be an item in current and future footprint analyses but were probably not considered in historical studies. These decisions lead to inaccuracies in the estimated total footprint, Eq. 3.2, as compared to top-down average per person emissions. The reasons are many-fold, as follows:

1. There is truncation error (Eq. 3.2).

2. The efficiency indicators and emission factors (Eq. 3.1) may be an outdated or not suitable for use in the analyst's country.

3. The amount of service (Eq. 3.1) provided by the consumer may be inaccurate due, among others, to

(a) Lack of knowledge of the consumer,

(b) Lack of patience by the consumer,

(c) Misinterpretation by the consumer of the analyst's data need, and/or

(d) Discretization by the analyst of the answer choices for the consumer so as to improve consumer participation (i.e., reduce inaccuracies $\mathrm{a}$ and $\mathrm{b}$ above).

So, how does one correct for this lack of accuracy? As a general strategy, I recommend that the analyst honors as many top-down values as possible and uses the bottom-up footprint analysis to provide lifestyle-based "color." This means that, in addition to the footprint study, one should have a set of results from a representative sample of the population.

To correct the bottom-up results to top-down, one could add a constant or apply a scaling factor to the bottom-up amount of services, or both. A problem with shifting the amount of services by a constant is that some services have a "true" zero, and a shift does not respect this "true" value. For example, the top-down mean amount of beef consumed is 
$92.5 \mathrm{~g} /$ person/day and the mean value from the representative sample is $85 \mathrm{~g} /$ person/day due to any or all of the reasons listed above. Then, the vegetarians and vegans will be not very happy if they are assumed to eat $7 \mathrm{~g} /$ person/day of beef due to the melding process. For services that have a normal distribution, both the application of a shift and of scaling achieve the new mean value. However, scaling is a better correction when applied to data that have a log-normal distribution, and many services or products approximate this distribution. With only one value as a benchmark (the top-down mean), one cannot calculate a scale and a shift.

I recommend that the analyst correct as many service or consumption values as he/she can to a top-down benchmark (Eq. 3.1) and make a second check against emission benchmarks if possible. The second check would correct against differences in the values of the efficiency indicator and emission factor (Eq. 3.1).

\subsection{An Actual Example}

As an example, let me explain the method I used for footprinting diet in the EU H2020 project, ECHOES. In ECHOES (https:/ / echoes-project. eu/), our goal was to estimate the personal energy demand via a survey for individuals in all EU countries. The entire detailed energy footprinting methodology is available in Bird et al. (2019). ECHOES food footprinting model includes 18 food types. ${ }^{3}$ As is the case, our survey was time limited to 10 minutes. So, we had space for only one question on diet. We asked the following:

Q: Please choose the answer that best describes your diet.

1. Meat in most meals

2. Meat in some meals

3. Meat very rarely

4. No meat, but fish

5. Vegetarian

6. Vegan

\footnotetext{
${ }^{3}$ The 18 food types are: Beer, Cheese, Coffee, Eggs, Fish, Fruit, Grains, Meat_beef, Meat_ chicken, Meat_pork, Milk, Nuts, Oil, Potatoes, Pulses, Sugar, Vegetables, and Wine. There was no distinction made between individual grains, vegetables, and fruits, as they have very similar LCA emission factors.
} 
As my top-down control, I used personal food consumption statistics from the Food and Agriculture Organization (FAO) of the United Nations (2021). I chose these data because (1) I needed consistency across the entire EU, and (2) the FAO data can include post-production losses and amounts for human consumption. These two points are important because one needs to match the consumption data with the assumptions made in the LCA emission factors. The emission factors assumed no postproduction losses and that animals consume feed. It is important to note that I did not assume nationally recommended consumption based on nutritional studies. Those are what we should eat, not what we do consume (eat + losses).

The methodology affects only the meat consumption and what is consumed in its place. For other food items, each respondent received the national average. To start, I assumed that vegans consumed the nutritionally recommended foods for a vegan diet. Then I assumed that answer 1 fit the national average meat consumption, that answer 5 (vegetarian) indicates eating no meat and that answers 2 and 3 indicate consuming $67 \%$ and $33 \%$ of the national average, respectively. For groups that ate less than the national average, the foregone calories provided by meat were replaced by nuts, oils, and pulses (spread equally across the three food groups). For the pescatarians (answer 4), I assumed that all meat calories were replaced by fish calories.

At this point, it should be clear to the reader that, with respect to the top-down control, I have underestimated the consumption of meat and overestimated the consumption nuts, oils and pulses. So, now I apply a scalar to the individual consumption of each food type so that the survey average value per food type equals the top-down control. It is important to note that using a scalar, the vegans and vegetarians still have no meat consumption. The answer 1 respondents, after correction, consume more meat than the national average. As a result, using a single question that is easily answerable by all respondents, I have created a realistic distribution of the consumption of food types. Even though the question has a subjective answer, the distribution has the correct average value. The adjusted consumption by food type was applied in Eq. 3.1 using EU-average LCA energy factors for each of the 18 food types. To make a GHG footprint, one need only use EU-average LCA emission factors instead of energy factors.

A point to consider is whether the top-down control should be a consumption value or an emission value. Here, the reader should remember 
that if she/he applies LCA emission factors in Eq. 3.1, some of the emissions might occur outside the national inventory. Balancing to the national inventory is only possible if the fraction of the emissions that occurs as part of the national inventory can be ascertained.

Now, I am certain that readers will be critical. You will undoubtedly suggest that more detail is needed, and I agree. However, the example illustrates the footprinter's conundrum. We were limited in regard to how many questions we could ask, and the survey respondent may not have good knowledge of the answer. For example, can you really tell me how many kilograms of wheat you consume in a year (including food waste)? In addition, in ECHOES, we were interested in the full personal energy footprint, and other segments of the economy, specifically consumption, housing, and transportation, were considered more important. Also, these are sectors where the respondent has good knowledge.

\subsection{CONClusions ANd Outlook}

In this chapter, I have presented my recommendations for calculating GHG emission footprints. I have tried to stress that there is really no "right" or "wrong" method to do this. The analyst must decide what type of emissions to use and which items and services to include in the footprint. He or she must clearly document these decisions so that the reader or user of the resulting footprint understands the limitations of the results. The decisions made by the analyst are made due to data availability, a priori understanding of the individual's response to the analyst's survey, consider the length of the survey and respondent's fatigue, and often include preselected focus areas for study. The next chapters discuss the development of a reliable questionnaire and the pitfalls associated with this approach. The derived questions and data were then used to estimate the GHG emissions and energy demand of the respondents based on the approach presented in this chapter. I have also tried to show that there are ways to correct the results so that they match top-down data and GHG emission estimates, which I believe should hold as benchmarks. Happy footprinting! 


\section{REFERENCES}

Bird, D. N., Schwarzinger, S., Kortschak, D., Strohmaier, M., \& Lettmayer, G. (2019). A detailed methodology for the calculation of cumulative energy demand per survey respondent. ECHOES project report 5.1.1. JOANNEUM RESEARCH Forschungsgesellschaft GmbH, Graz, Austria.

Čuček, L., Klemeš, J. J., \& Kravanja, Z. (2012). A review of footprint analysis tools for monitoring impacts on sustainability. Journal of Cleaner Production, 34, 9-20.

Davis, S. J., \& Caldeira, K. (2010). Consumption-based accounting of CO2 emissions. PNAS, 107(12), 5687-5692.

FAO. (2021). FAOSTAT: New food balances. Retrieved February 25, 2021, from http://www.fao.org/faostat/en/\#data/FBS

Fuchs, R., Brown, C., \& Rounsevell, M. (2020). Europe's green deal offshores environmental damage to other nations. Nature, 586(7831), 671-673.

IPCC. (2006). 2006 IPCC Guidelines for national greenhouse gas inventories. Prepared by the National Greenhouse Gas Inventories Programme. Edited by Eggleston H.S., Buendia L., Miwa K., Ngara T., \& Tanabe K. IGES, Japan.

Jungmeier, G., Bird, D. N., Lettmayer, G., Hingshamer, M., \& Schwaiger, H. (2020). Abschätzung der konsumbezogenen Treibhausgas-Emissionen der Stadt Wien: Status Quo, Lebensstile und Maßnabmen. Report LIFE 2020/1. JOANNEUM RESEARCH Forschungsgesellschaft GmbH. Graz, Austria.

Liptow, C., Janssen, M., \& Tillman, A.-M. (2018). Accounting for effects of carbon flows in LCA of biomass-based products-Exploration and evaluation of a selection of existing methods. The International Journal of Life Cycle Assessment, 23(11), 2110-2125.

Mulrow, J., Machaj, K., Deanes, J., \& Derrible, S. (2019). The state of carbon footprint calculators: An evaluation of calculator design and user interaction features. Sustainable Production and Consumption, 18, 33-40.

Padgett, J. P., Steinemann, A., Clarke, J., \& Vandenbergh, M. (2008). A comparison of carbon calculators. Environmental Impact Assessment Review, 28(2-3), 106-115.

Peters, G. P. (2008). From production-based to consumption-based national emission inventories. Ecological Economics, 65(1), 13-23.

Windsperger, A., Windsperger B., Bird D. N., Jungmeier G., Schwaiger H., Canella L., Frischknecht R., Nathani C., Guhsl, R., \& A. Buchegger. (2017). Life cycle based modelling of greenhouse gas emissions of Austrian consumption. 
Final Report of the Research Project ClimAconsum to the Austrian Climate and Energy Fund, Vienna. Institut für Industrielle Ökologie (IIÖ). St. Polten, Austria. https://www.klimafonds.gv.at/wp-content/uploads/sites/6/201 70913climAconsumACRP7EBB464796KR14AC7K11791.pdf

Wood, R., Neuhoff, K., Moran, D., Simas, M., Grubb, M., \& Stadler, K. (2019). The structure, drivers and policy implications of the European carbon footprint. Climate Policy, 20(Sup 1), S39-S57.

Open Access This chapter is licensed under the terms of the Creative Commons Attribution 4.0 International License (http://creativecommons.org/licenses/ by $/ 4.0 /$ ), which permits use, sharing, adaptation, distribution and reproduction in any medium or format, as long as you give appropriate credit to the original author(s) and the source, provide a link to the Creative Commons licence and indicate if changes were made.

The images or other third party material in this chapter are included in the chapter's Creative Commons licence, unless indicated otherwise in a credit line to the material. If material is not included in the chapter's Creative Commons licence and your intended use is not permitted by statutory regulation or exceeds the permitted use, you will need to obtain permission directly from the copyright holder.

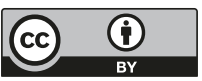

